\section{UCDNN}

LIBRARY
University of Connecticut OpenCommons@UConn

Philosophy Articles

Philosophy Department

$1-1-2008$

\title{
Against Universal Mereological Composition
}

Crawford Elder

University of Connecticut Department of Philosophy, crawford.elder@uconn.edu

Follow this and additional works at: https://opencommons.uconn.edu/philo_articles

Part of the Philosophy Commons

\section{Recommended Citation}

Elder, Crawford, "Against Universal Mereological Composition" (2008). Philosophy Articles. 10.

https://opencommons.uconn.edu/philo_articles/10 
Crawford L. Elder; Philosophy Department, Unit 2054; University of Connecticut; Storrs, CT 062792054; U.S.A. The final and definitive version of this paper appears in dialectica, 62 (2008), pp. 433-54. This earlier draft of the paper is posted here by the kind permission of dialectica, the European Society for Analytic Philosophy, and Blackwell Publishing. Both this draft and the published version are copyrighted: Copyright 2008, Crawford L. Elder.

\section{Against Universal Mereological Composition}

Abstract. This paper opposes Universal Mereological Composition. Sider defends it: unless UMC were true, he says, it could be indeterminate how many objects there are in the world. I argue that there is no general connection between how widely composition occurs and how many objects there are in the world. Sider fails to support UMC. Moreover, we should disbelieve in UMC objects. Existing objections against them say that they are radically unlike Aristotelian substances. True, but there is a stronger objection. This is that they are characterized by no properties, and so fail to be like anything-not even themselves.

Few theses widely accepted among philosophers who work in metaphysics seem more outlandish, to people who work in other areas, than that of Universal Mereological Composition. This is the thesis that for any objects whatever-however arbitrary it may seem to consider them together-there is a further object of which those objects are parts. This further object is sometimes said to be "an ontological free lunch": its existence, its defenders say, just is the existence of its parts (Armstrong 1997, pp. 12-13 and 185). It is natural, when thinking along these lines, to suppose that the identity of this mereological object is given by the identity of its parts - that this object could not have had different parts from its actual ones, and that necessarily this object exists exactly where and when its actual parts exist. ${ }^{1}$ Some philosophers, it is true, use the phrase "mereological sum" (or "mereological sum of...") to designate objects for which these modal claims do not hold (van Inwagen, 2006; Saucedo, forthcoming). But the mereological objects on which this paper focuses are objects to which the mereological essentialism, implicit in the slogan "ontological free lunch", does apply (as do the associated claims about spatial and temporal location). It is these objects that most philosophers have in mind when they speak of "mereological sums", and these objects that most philosophers take the thesis of Unrestricted 
Mereological Composition to affirm (Baker 2000, pp. 179-85; Lowe 1989, Ch. 6; Wiggins 1980, pp. 3034; Sidelle 1998, pp. 430-433; Sanford 2003). In the last section I will defend this restricted focus.

The thesis that there is a mereological object, for any arbitrary plurality of objects, is treated as being neutral on the question of which objects are there to be welded into mereological sums. Perhaps these objects include only the microparticles of physics, or only these together with persons, or perhaps they also include the familiar inanimate objects in which common sense believes. The thesis is just that mereological summing always yields a real object, provided it starts with real objects. This neutrality about fused objects explains why the examples usually given of these mereological objects typically have, as their parts, such familiar objects as stars and tennis shoes and the Eiffel Tower (Rea 1998, p. 248; Merricks 2001, p. 51)—even though very, very few philosophers currently working in metaphysics today defend the reality of such familiar objects as these.

This paper opposes Universal Mereological Composition (henceforth "UMC"). I begin by examining the most appealing argument for UMC in the recent literature. This is the argument, taken by Ted Sider from materials in David Lewis (Lewis 1986, pp. 212-13), that forms the basis for Sider's argument for four-dimensionalism (Sider 2001, pp. 120-39). Assessment of this argument is thus of interest beyond the topic of UMC. I argue, amplifying an objection by Kathrin Koslicki (2003), that Sider's argument rests on a claim that would be rejected by those whom the argument seeks to persuade (as Koslicki partly points out) and that is strangely unmotivated (since the claim forgets that, at various places in the world, there are stuffs and matters such as butter or coffee or petroleum).

I then turn from arguing that UMC is unsupported to arguing that it is false. UMC is sometimes treated by its own advocates as sounding odd and counterintuitive (Lewis 1991, pp. 79-81); nevertheless, few concerted objections have been offered against it. The objections that have been offered generally ${ }^{2}$ focus on a special extension of UMC - namely the thesis, discussed in section II, that there are in the world diachronic mereological objects—and present one version or other of the idea that these objects are profoundly unlike the Aristotelian substances in which common sense believes, since the later stages in the careers of these objects typically do not causally reflect, or intelligibly grow out of, the earlier stages 
(Koslicki 2003, pp. 125-28; Thomson 1983, p. 213). The motivation here appears to be to get adherents of UMC to take more seriously the sorts of features that common sense (and perhaps empirical science as well) looks for, in judging about which objects populate the world.

The objection against UMC that I will offer differs from these existing objections both in content and, to a mild degree, in motivation. For the existing objections seem to me unlikely to carry any weight in the contemporary climate in metaphysics. They have thus far elicited no responses from adherents of $\mathrm{UMC}$, and the reason for this, I surmise, is that the dominant presuppositions of debate in metaphysics make it virtually unnecessary for the adherents to respond. These presuppositions assign at best negligible weight, for the purposes of serious ontology, to the sorts of features that common sense (and even empirical science) goes by, in judging which objects are out there. Consequently the project of reawakening a latent allegiance to these features, among current adherents of UMC, is forlorn.

One of my main motivations is to identify these presuppositions, and to point out that they are both questionable and optional. My hope is that by exposing these presuppositions to light, and to the abrasion of critical thought, I can initiate their decay. My other main aim is to present an objection against UMC that will carry weight even when viewed from the standpoint that incorporates these presuppositions. What I will argue is that the "structural" properties, which are the only properties that would characterize the typical UMC object, are not genuine properties at all. Typical UMC objects, then, simply have no properties at all. This objection does not say: we should not believe in such objects, since they fail to be like Aristotelian substances. Rather it says: we should not believe in such objects, since they fail to be like anything-not even themselves.

Sider's argument for UMC (Sider 2001, pp. 120-39) has the form of a reductio. The hypothesis that UMC is false amounts to saying that it is not the case that for just any and every class of objects, there exists a mereological object of which those objects are all parts (and such that any part of the 
mereological object overlaps one or more of the objects in the class): it denies that every class has a fusion. What it asserts, in the phrase that Sider borrows from Lewis, is that composition is restricted. The argument itself has the form of a sorites. One envisions a continuous series of cases, stretching from an extreme at which composition definitely does not occur - there is only a plurality of objects, and not some single object which the members of the plurality jointly compose- to a case in which composition definitely does occur. There is, across the series, a progressive increase in whatever features it is, that the opponent of UMC thinks of as making for composition-perhaps spatial proximity, perhaps causal integration, perhaps qualitative homogeneity, perhaps a combination. This picture gets stated in the first premise of Sider's argument, and the following two premises do the real work (2001, pp. 123-25).

P1: If not every class has a fusion, then there must be a pair of cases connected by a continuous series such that in one, composition occurs, but in the other, composition does not occur.

P2: In no continuous series is there a sharp cut-off in whether composition occurs.

P3: In any case of composition, either composition definitely occurs, or composition definitely does not occur.

As Sider rightly points out (p. 125), it is the last premise that is the most controversial. A philosopher who thinks that baldness is "restricted"- that not just every person is bald, though some are-would probably deny that baldness is crisply restricted. She would more likely claim that there are borderline cases. Just so, the philosopher who thinks that composition is restricted might very well think that there are cases in which the objects in some class neither definitely compose a larger object, nor definitely fail to compose such an object. P3 needs defense, and Sider undertakes to defend it (p. 125 f).

The defense proceeds from this thought: if in some class there are $n$ objects, and those objects together compose an object-if, that is, the class has a fusion-then there exist, with respect to that segment of the world, $n+1$ objects. If on the other hand there can be borderline cases of composition, then with respect to the segment of the world containing some class of $n$ objects, it will neither be determinately true that there exist $n+1$ objects, nor determinately false. Thus we should believe the following conditional: 
(N) If there can be borderline cases of composition, then, for some finite and nonempty world, there is a numerical sentence that is indeterminate in truth-value.

"Numerical sentences" are ones that "contain only logical terms and the predicate 'C' for concreteness" (p. 127). Thus a numerical sentence that says that there are in the world three objects reads as follows:

$\exists \mathrm{w} \exists \mathrm{x} \exists \mathrm{y}[\mathrm{Cw} \& \mathrm{Cx} \& \mathrm{Cy} \& \mathrm{w} \neq \mathrm{x} \& \mathrm{w} \neq \mathrm{y} \& \mathrm{x} \neq \mathrm{y} \&(\mathrm{Az})(\mathrm{Cz} \rightarrow[\mathrm{z}=\mathrm{w}$ V z=x V z=y])]. (In quasi-English: "there is something and something and something, such that each 'something' is concrete and distinct from the others, and such that anything else concrete that there may be is identical to one of these 'somethings'.)

Soon I will argue that $(\mathrm{N})$ is in fact unmotivated. But at first blush it certainly seems eminently reasonable, and so let us ask how the opponent of UMC might reconcile himself with its apparent truth. The opponent affirms the antecedent. But how—asks Sider, echoing Lewis—could the consequent possibly be true? There is nothing ambiguous or vague about " $(\exists x) \ldots x \ldots$... and “(Ax)...x...”, provided we are considering — as we should—unrestricted quantification. (In English: nothing ambiguous about "there's an $\mathrm{x}$ such that $\mathrm{x} . .$. " or "for all $\mathrm{x}, \mathrm{x} . .$. .) There is nothing ambiguous about “...=..." or about “......”. (Nothing ambiguous about “...is identical with...” or “...is not identical with...”.) A numerical sentence says nothing vague. So how could it possibly be indeterminate in truth-value?

Koslicki offers this response: it all depends on what sort of a world it is, that the sentence is quantifying over (2003, pp. 118-19). If there really can occur in the world borderline cases of composition, then there will be numerical sentences that speak precisely about a vague situation, and these will be numerical sentences whose truth is indeterminate. This response presupposes that not all vagueness need be vagueness in speaking: it rejects "the linguistic theory of vagueness", and maintains that vagueness can obtain out there in the world. Sider does consider this sort of response. He writes, "I mention this position only to set it aside; as I said above, I simply assume that this theory of vagueness is not correct" (p. 129). 
But this renders Sider's "defense" of P3 inconclusive. The "defense" rests on $(\mathrm{N})$, and yet it simply refuses to speak to those philosophers who are unpersuaded that $(\mathrm{N})$ always sets up a modus tollens.

Here is a less confrontational version of the same sort of objection. Consider a finite world in which there are some banyan trees. A banyan tree is a most remarkable organism. As the branches grow they send out tendrils that reach downwards. These eventually reach into the earth, establishing roots; they can grow to look like secondary trunks; they even can grow to be as thick as the original trunk. Where there are well-established banyan trees, there seems to be no clear answer to how many banyan trees there are-and the problem seems to lie not with us and our ways of knowing, but with the world. I hasten to add that banyan trees are not a flukeish "trick example". Aspen trees are connected at the roots, and it can happen, in autumn, that a stand of aspens divides into large segments, each uniformly bearing its own distinctive coloration. There is a fungus below ground in northern Michigan which some count as being "the largest organism" in the world, though here too the count seems inherently contestable. Hegel found such examples to be of philosophical interest: he maintained that the plant kingdom was the area of nature in which individuality itself was attenuated (Hegel 1970, §§ 343 and 347-48).

Which numerical sentence will be determinately true of a finite world containing mature banyan trees? None, it seems. If we opt for a numerical sentence that features relatively many existential quantifiers, we run the risk that some of the clauses asserting non-identity are false. If we opt for a numerical sentence that features relatively few existential quantifiers, we run the risk that the universally quantified conjunct is false. In a world containing mature banyan trees, identity and distinctness seem to be vague. Sider considers this response as well. He writes, "I find this doctrine obscure but have nothing to add to the extensive literature on this topic; here I must presuppose it false" (p. 130). Again, Sider's "defense" of P3, by way of $(\mathrm{N})$, is inconclusive: it does not address a reason for thinking that certain numerical sentences might fail to be true.

But the challenge I have lodged against $(\mathrm{N})$ invites a response to which Koslicki's original challenge is immune. The proponent of UMC could simply deny that there are banyan trees out there in 
the world, to be quantified over. The proponent might elect to maintain that, apart from mereological fusions, there are only crisply-individuated objects, such as the microparticles of physics. But there are two problems with this rejoinder, a great and a small. The small problem is that at least some microparticles fail to be as crisply individuated as one might hope. An electron captured by an ionized helium atom becomes superposed with the one electron that is already there, with the apparent consequence that, if the atom again undergoes ionization, there is no fact of the matter as to whether the electron later stripped off was or was not the electron that was earlier gained (Lowe 1998, p. 62). The large problem is that, as I noted at the outset of this paper, UMC is treated as neutral with respect to which objects there are in the world, to be welded into mereological sums: it says only that mereological summation always yields a real object, provided it starts with real objects, whatever these may be. Thus the defense of UMC should not presuppose a particular ontology, a particular roster of which objects are really there.

In any case, there is room to wonder whether, as a general matter, $(\mathrm{N})$ is a well-motivated claim at all. That is, there is room to wonder whether the question of how much composition occurs in the world has, in general, anything to do with how many objects there are in the world. For suppose that the $n$ microparticles in some class between them compose some butter, or some wine, or some coffee. Which numerical sentence is rendered true by this instance of composition? To answer that question, it seems, we would have to say how many butters there are, or how many coffees the $n$ microparticles have composed, or how many wines. But these questions are ill-formed: "butter", "wine", and "coffee" are non-count nouns. We might also ask—for anything Sider has shown—what happens if there is, on the part of the $n$ microparticles, only a borderline instance of composing-butter or composing-coffee. Has the borderline character of the composition robbed determinate truth from some numerical sentence?

Of course there are, in the philosophical lexicon, a number of count nouns that can be used to talk about what is there, where there is some butter or some wine or some coffee. One can speak of a "parcel" or a "sample" or an "aggregate", and one can set about counting "parcels" and "samples" and “aggregates". There is an ancient tendency among philosophers, recently well documented by Henry 
Laycock, to discern unitary objects when dealing with the parts of the world that contain butter or wine or coffee (Laycock 2006, Chapters 2-4). It is connected with a tendency to ignore the fact that some noncount nouns are, semantically, non-atomic: that is, that they do not, as a function of their meaning, divide their reference over discrete units (Laycock 2006, pp. 135-39; cf. Lowe 1998, pp. 161 and 72-74). Before these tendencies again spring into play, let me say some things about the coffee that is there before us, on an occasion that I shall describe, and say it using only a philosophically innocent count-noun that occurs in ordinary usage, namely "portion”.

The office assistant brings into the business meeting a large, full carafe of coffee. From it he pours coffee for each of the eight people participating in the meeting (cf. Laycock, p. 49). The first five people receive full cups; the sixth through eighth, a cup only half-full. But Person \#7 is assertive, and asks the assistant for more coffee. The office assistant obliges, and the carafe is now empty.

How many portions of coffee are there in the conference room? One could say that the very large portion of coffee that the assistant brought in in the carafe is still there, but is now spatially discontinuous: it is separated across the eight cups. One could say that there are eight portions of coffee in the room. But what about Person \#7-didn't he receive a second portion? Yet Person \#1 has no more coffee in his cup than Person \#7 now has. So does Person \#1 have two portions? And what about the coffee in the bottom two inches of Person \#2's cup? It is coffee, and so it is some coffee, and so it is a portion of coffee.

There is simply no fact of the matter, I suggest, as to how many portions of coffee there are in the conference room. There is much coffee in the room, to be sure. But there being much coffee there makes no contribution to the truth conditions for any numerical sentence. Nor would the truth of any numerical sentence be rendered indeterminate, if the coffee had been quite badly made, and were only barely coffee at all. If the $n$ microparticles in some class of microparticles only borderline-compose coffee, it does not follow that some numerical sentence is only borderline true. Thus how widely composition occurs in the world does not, as a general matter, have bearing on how many objects there are in the world—as (N) alleges. (Note that this argument focuses on the outcome of composition, when $n$ microparticles compose 
some butter or some coffee, and not on the nature of that composition. Maybe the composition is mereological, maybe it is not—-that is, maybe only the individual microparticles that in fact now compose some coffee could have composed that very coffee, and maybe not. The point is that however we end up with some coffee, there is not a number of the coffee(s) that we end up with.)

The challenge to $(\mathrm{N})$ that I am drawing, from the existence in the world of coffee and butter and wine, is in one way like the challenge to $(\mathrm{N})$ that I draw from the existence of banyan trees. The proponent of UMC can defeat it by electing a particular ontology. She can deny that there is such a thing as butter, or such a thing as coffee, at all: instead, she can claim, there are only the many microparticles that, according to me, here and there and there again compose some butter or some coffee (together with the myriad mereological sums that incorporate those microparticles as parts). But again, this way of preserving the argument for UMC threatens the ontological neutrality that the doctrine, once established, is generally treated as having.

If we do allow that there may be in the world such things as coffee and lemonade, there is indeed one other way in which we might wonder why there need be any connection at all between how much composition occurs in the world, and how many objects there are in the world. The "cases of composition" that Sider discusses are all cases in which some non-fuzzy class of objects—some class containing exactly $n$ elements-has (or fails to have) a fusion. But it is not clear that all composition is like this. "If you take some water and some lemon juice," Granny might have said, "and some sugar and a little salt, and if you mix them thoroughly together in just the right proportions, you will end up with some lemonade". It would be a mistake for a proponent of UMC to argue for her view by denying that what Granny said is true. But if Granny's utterance can be formalized, it must be formalized using the plural quantification that Boolos developed (see Laycock 2006, Ch. 4). 
UMC objects, if there are such things, are deeply strange from the standpoint of common sense and even from that of empirical science. Does their strangeness furnish materials for arguing that such objects do not exist? I will begin on this question by surveying the respects in which typical UMC objects are strange. But I should add that by "typical" I do not mean "statistically normal". UMC objects, if real, are fathomlessly numerous, and there is no prospect of counting them. Rather what I mean by "typical" UMC objects are ones that stand out as outlandish, by virtue of contrasting so greatly with the familiar objects of common sense and empirical science. Almost always these will be UMC objects that comprise very many parts, and often the parts will be considerably separate from one another spatially. Some UMC objects derive their appearance of strangeness from comprising parts that intuitively seem to belong to different ontological categories-e.g. microparticles together with baseball stadiums together with parts of noses-and others are strange in ways that rest on their comprising parts that all belong to the same ontological category. So I shall include UMC objects of both these sorts among "typical" ones.

The most obvious way in which UMC objects contrast with familiar objects such as dogs and desks and trees, or even atoms and cells, is that they are incapable of gaining or losing parts. For their identities are dependent on the identities of their parts. That is, for any UMC object there is a fixed plurality of parts such that, necessarily, the object exists exactly as long as all those parts exist. Moreover, across the span of its existence, any UMC object necessarily is spatially present—partially spatially present, to speak precisely-in every volume of space that is occupied by one of those parts, and only in those volumes of space. ${ }^{3}$

It follows that UMC objects can survive the spatial dispersal of their parts, and therein consists a second divergence from familiar objects. In this way, UMC objects are considerably more durable than dogs or desks or molecules. UMC objects composed wholly of atoms are indeed nearly indestructible, and have a past that is incalculably ancient. Yet in another way UMC objects are more fragile than 
familiar objects. They cannot survive the annihilation of even a single part, however small. This entails that there are countless UMC objects that are extremely unstable and short-lived. In the volume where common sense discerns a tree, for example, numerous UMC objects are spatially present—partially spatially present, to speak precisely — that all comprise, as a part, some atomic nucleus that will undergo beta decay at an objectively unpredictable point over the next few seconds. Indeed if UMC objects exist, sentences of the form "in the volume of space now before me, an object is present that would cease to exist under the following circumstances:..." have innumerable true completions.

It has been argued that typical UMC objects (if real) cause nothing, and have no causal powers (Elder 2004, Ch. 3). For consider: in 1996, Ian Wilmot caused the birth of the first cloned sheep, who was named "Dolly". But it is false that in 1988, I, together with the adult population of Idaho, and together with Ian Wilmot, caused the birth of "Dolly". I had nothing to do with it, and neither did the people in Idaho (Elder 2004, 2001, 2000.).

Do these strange features create obstacles for claiming that there really are in the world UMC objects? Many philosophers suppose that they at least create obstacles for the claim that familiar objects can be "reduced" to UMC objects—-the claim, in other words, that UMC objects are what the folk and the scientists "really are talking about" when they talk about dogs and desks and cells. For in that case the folk and the scientists would hold wildly inaccurate beliefs about the spatio-temporal careers, and the modal properties, of the objects they "really are talking about"- too wildly inaccurate for the claim of “reduction" to be plausible (Wiggins 1980, pp. 30-34; Sidelle 1998, pp. 430-433; Sanford 2003). If UMC objects really exist, then, we must either be eliminativists with respect to familiar objects, or must hold that there is massive Coincidence between familiar objects and UMC objects. But eliminativism is widely considered to be a tenable view. ${ }^{4}$ And if the prospect of Coincidence raises difficult philosophical questions, UMC objects are not solely responsible for them: even if the tree before me does not coincide with a tree-plus-soon-to-decay-nucleus, it still coincides (so many say) with a large "parcel" of cellulose, which again differs in its career and its modal properties from the tree (Rea 1997). 
But many proponents of UMC do consider it useful to respond to the complaint that UMC objects, unlike the typical objects recognized by common sense and by empirical science, are incapable of gaining or losing parts. They respond by maintaining that there are, in addition to the synchronic merelogical fusions that we have so far considered, diachronic mereological fusions. These are, so to speak, temporally cross-cutting UMC objects. Each such object is constituted by "an assignment", a function from times to objects existing at that time (Sider 2001, p. 133). A diachronic mereological fusion ("D-fusion", to use Sider's term) is then said to have, as its parts at each of these times, all and only those objects onto which the assignment maps that time. Since the assignment can map different times onto different pluralities of objects, it follows that a D-fusion can have, at different times, different parts; since the assignment can map different times onto greater and lesser pluralities, the D-fusion can be said to comprise more parts at one time, fewer at another. The D-fusions of greatest interest for proponents of UMC are "minimal D-fusions", ones that exist only at the times over which the assignment is defined (Sider 2001, p. 133). For the natural way to extend the idea of universal mereological composition to diachronic fusions is to say: any temporal cross-cutting yields an object; more precisely, corresponding to any assignment there really exists a minimal D-fusion. So far as the definition of a minimal D-fusion goes, and barring special argument to the contrary, a minimal D-fusion can even exist at discontinuous times (Sider 2001, p. 136). The UMC objects we considered before can be spatially discontinuous, but not temporally discontinuous; these further UMC objects can be both spatially and temporally discontinuous.

At least some of the interest in expanding UMC so that it asserts the existence of minimal Dfusions comes from the fact that these objects, by virtue of being capable of gaining and losing parts across time, are better qualified to stand in for the mereologically changeable objects in which common sense and empirical science believe. But in other respects minimal D-fusions are radically unlike the changeable individual substances in which the folk and the scientists believe, and these differences have seemed to some philosophers to show that it is a mistake to regard minimal D-fusions as real at all. The central objection here emerges if we consider a "typical" minimal D-fusion- "typical" in the sense, once 
again, of being outlandish in a way that distinguishes minimal D-fusions from familiar objects—such as Lewis' "trout-turkey" (Lewis 1991, pp. 79-81). This is an object that for a fair stretch of time is a trout swimming in a brook, and for a subsequent stretch of time, beginning immediately after the first stretch, is a turkey in a pen. The qualitative character of the later phases in this object's existence appears not to be causally regulated by, nor understandably to grow out of, the qualitative character of the object's earlier phases. And once we see the apparent causal discontinuity in the career of the trout-turkey, we can see how there could be even more radical discontinuities in the careers of other "typical" minimal D-fusions. One such object exists here up until 12:00 noon, and one second later exists at a location 187,000 miles away from here, thus appearing to have traveled faster than the speed of light. Other such objects, by virtue of sudden and dramatic alterations in their number of parts, appear to violate principles of conservation of mass/energy (Balashov 2006, pp. 527-28). Typical minimal D-fusions go out of existence at certain points in time, not because of anything that has happened to them, but simply because "their time was up" (Koslicki 2003, p. 127). Similarly, if we ask what causes a typical minimal D-fusion to come into existence at the time very time that it does, rather than a bit earlier or later, the only answer will be "it was time for it to start"—-such entities appear to have been created ex nihilo (Thomson 1983, p. 213).

But proponents of UMC have not sought to rebut these objections against the reality of minimal D-fusions, nor have they spoken to the milder reservations about the reality of synchronic mereological fusions (i.e., our original UMC objects) canvassed above-not even the reservation that typical synchronic mereological fusions have no causal powers. I suggest that the reason for this non-response is that, given the prevailing presuppositions of contemporary debate in metaphysics, all these objections and reservations have seemed simply beside the point. It is as if proponents of UMC said to themselves: "Some of these worries show that many of the mereological fusions that exist in the world are not of interest to science-tracking such objects, and documenting their ways, would not serve the goals of science. Other worries show that we could not distinguish all the mereological fusions that are present (partially) at a given place at a given time, even if we wanted to. Yet other worries may even show that 
neither the folk nor the scientists have any reason to want to track or reidentify or individuate mereological fusions: it may really be true that typical mereological fusions cause nothing, and make no difference in how the world works. But all of this does not even begin to speak to the question of whether mereological fusions are there, whether they exist. To give these worries any bearing at all on the question of whether mereological fusions exist, one would have to couple them with a pragmatist picture of reality, or with verificationism. If one could say that for an object to be real is for it to engage our projects and be of practical importance to us-or if one could say that the reality of any object requires the availability of an empirical test that will unequivocally attest to its reality-then indeed the worries surveyed here might be relevant to the claim that the vast majority of the mereological sums we believe in do not exist. But pragmatism and verificationism are positions of the past. Debate in metaphysics currently supposes that existence may be entirely independent of the domain of our interests and the reach of our cognitive capacities.”

It would be a very large undertaking indeed to show that even if (as I believe) these are the prevailing presuppositions of debate in metaphysics, they should not be-that these presuppositions are false. But I can point out that this understanding of what metaphysics can legitimately presuppose is optional. A different understanding is possible. The first element of it would treat, as simply a bedrock truth about the world—resting neither on pragmatism nor on verificationism — the claim that elements of the world are such as to act on other elements of the world, and in this way are such as to manifest their existences. The second element would be to say that we are ourselves items in the world, and are among the elements of the world that get acted on. That is, the second claim would be that our cognitive capacities have been fashioned by a long history of natural selection, and that our interests and goals are the outputs of programs in us that natural selection has installed. Throughout this history of natural selection, it has been crucial for us to respond to objects that are fully mind-independent. So the appearance that certain objects engage our practical interests, or matter crucially for our cognitive undertakings, is prima facie evidence that those objects are mind-independently real. At the same time the power of our cognitive capacities, and the scope of our interests, combine with the first element of this 
picture - the idea that elements of the world tend to manifest their existence by acting on other elements - to create a presumption against the idea that there could be a whole class of objects that is in principle of no relevance or importance for our science or our practice.

III

If UMC objects really exist, what are they like—by what properties are they characterized? I begin this section by arguing that in "typical" circumstances-circumstances that bring out what is distinctive and strange about UMC objects-UMC objects are characterized only by so-called "structural properties" (Armstrong 1997, pp. 32-38). I then introduce the reasons for thinking that, while some "structural properties" are properties of a perfectly genuine sort, the "structural properties" that would characterize typical UMC objects are not properties at all. In the next section I offer a fuller and more sophisticated version of the case against the "structural properties" by which typical UMC objects would typically be characterized.

We can readily imagine circumstances in which UMC objects would be characterized by a number of familiar properties—but the objects would have these properties only accidentally, and the circumstances would be decidedly atypical. Thus consider, to begin with, a UMC object of our original sort—a synchronic mereological fusion—and suppose that the parts of this object are individual atoms. If it just so happens that these atoms are spatially close to one another, so that collectively they form a compact, separately moveable mass of matter, then the fusion of these atoms can be said to have a certain mass, a certain velocity, perhaps even a certain color and shape and elasticity— the fusion might be said to have just the properties of an orange toy ball. But the all of these properties except the first will be only accidental properties of that synchronic fusion (see section V). That very fusion can go on being itself even if the atoms become widely dispersed, and could even now have been itself if the atoms had now been widely dispersed. Yet if the atoms - the parts of this UMC object—were widely dispersed, this UMC object would not be a possible object of sight or of touch, and so would have neither a color nor a 
shape nor an elasticity. Nor can it be said that a widely scattered plurality of atoms, each moving in its own way or standing at rest, collectively has a velocity (Lowe 2003, p. 707). Only aggregate mass would remain. And certainly dispersal is the more "typical" case. That is, what is distinctive and strange about synchronic UMC objects is, in large measure, that so often they are spatially discontinuous objects.

Or consider a diachronic mereological fusion, all of whose elements again are atoms, that just happens to take up the very four-dimensional volume in which common sense would take there to be a dog. Then this diachronic UMC object might be said to have a particular gait or odor or even a particular bark or disposition. But all that is essential to this diachronic UMC object is that, at each of the moments it exists, it comprises just those atoms that it actually comprises, and hence just that those atoms exist. It does not matter where those atoms are, nor whether they are spatially associated with one another-that is the force of saying that the object is a diachronic mereological fusion (see section V). So at each of the moments over which the assignment for this diachronic UMC object is defined, the atoms that compose it could have been widely dispersed. The gait, the odor, and the bark are accidental properties of the diachronic UMC object. They obtain, moreover, only thanks to a spatial association that is decidedly "atypical". That is, what is distinctive and strange about mereological objects of any sort is precisely that they are mereological: their parts need not be arranged one way or another, but need only be, in order for the object to exist.

Is it in fact right to say that the whole nature of a mereological object is exhausted by the mere existence of its individual parts - that in typical circumstances, a mereological object can claim, as a unitary whole, no qualitative character of its own? Apart from the single property of aggregate massmore precisely, of aggregate-mass-at-a-time - this very nearly is right. If mereological objects have, as wholes, distinctive qualitative characters at all—characters that can set one such object off from othersthose characters will consist in having one or another "structural property". A "structural property" is one that can be specified only by a conjunction, each conjunct of which depicts the property-bearer as having a part that meets a certain description. The standard example is the structural property that is characteristic of methane molecules (Armstrong 1997, pp. 32-38). A methane molecule is characterized 
by: having one part that is a carbon atom; having another part that is a hydrogen atom and that shares an electron with a carbon atom; having another part that is a hydrogen atom that shares an electron with a carbon atom; having yet another hydrogen-atom part that shares an electron with a carbon atom; and having yet another again. This same structural property can be specified in a slightly different way, namely by spotlighting, in each of five conjuncts, just the intrinsic character of each of the five atoms in the methane molecule, then using a sixth conjunct to indicate the relations that obtain among the five atoms. The alternative formulation is important, since it provides a template for identifying structural properties that will characterize mereological objects across typical circumstances as well as atypical ones. For the nature of a mereological object requires no particular relations among that object's parts: the object's existence requires only that each of the individual parts exists; hence the specification of a structural property that reliably characterizes a mereological object will be like the second formulation of "the methane property", but without the sixth conjunct. Every conjunct in this specification will say only what some one part of the mereological object intrinsically is like. Mereological objects may accidentally bear richer structural properties, such that specifying these properties requires indicating, in one or more of the conjuncts, relations among the parts. But the structural property that is essential to any UMC object - the property that characterizes that UMC object's very nature-will be one that incorporates no particular relations among the parts of the object.

My contention, as I indicated in the introduction, is that some so-called "structural properties" are not genuine properties at all. One might wonder what I could possibly mean by such a claim—how could “a so-called property" fail to be a property? But on almost everyone's intuitions, there are some locutions of the form "the property of being..." that fail to pick out a genuine property. "The property of being such that Des Moines is in Iowa" is a fairly uncontroversial example. What I am claiming is that properties that are genuine in the sense of being ways for things to be-of constituting answers to the question of what something is like - do not include certain so-called "properties", and in particular not the "structural properties" that characterize typical mereological objects. I do not rest this claim on intuition. Rather I rest it on the position, found both in Aristotle and Hegel, that any genuine property contrasts with 
its own proper contraries (Aristotle, Physics Bk. I, Ch. 5; Bk. V, Ch. 1 and Ch. 5; Hegel 1873, §§ 89-98; Hegel 1969, pp. 109-137 and 600-622). One way of putting this position is that the very identity of a genuine property consists (at least partly) in its contrasting, sharply or mildly, with certain other properties. Another formulation focuses on property-bearers: it says that what it is for a thing to have a certain genuine property is (at least in part) for it thereby to differ, to greater and lesser degrees, from things bearing certain other properties.

The key idea, on either formulation, is that for there even to be properties, there must be contrariety. Contrariety is like incompatibility, but involves more. The property of having an adult weight of 25-to-30 pounds is incompatible with the property of having an adult weight of 3-5 pounds, but is also incompatible with the property of having an index of refraction of 1.414; only an animal can have an adult weight of 25-to-30 pounds, and no animal can be a liquid (or a portion of a liquid). Yet it seems to lie in the very nature of having an adult weight of 25-to-30 pounds that it excludes, and contrasts with, having an adult weight of 3-5 pounds. It seems not to lie in the very nature of that property that it excludes having an index of refraction of 1.414. One way of unpacking this thought, as Bigelow and Pargetter have shown (Bigelow and Pargetter 1990, pp. 53-62), is that having an adult weight of 25-to-30 pounds contrasts to different but commensurable degrees with other adult body weights: having an adult weight of 25-to-30 pounds contrasts more sharply with having an adult weight of 3-5 pounds than with having an adult weight of 10-15 pounds. But the difference between having an adult weight of 25-to-30 pounds and having an index of refraction of 1.414 is neither greater nor lesser than either of these differences; it is incommensurable with those differences, being a complete lack of connection. That is what it means to say that for the property of having an adult weight of 25-to-30 pounds, other adult body weights (or weight-ranges) count as "its own proper contraries".

The question whether "structural properties" are genuine properties, from the standpoint of this position, is the question whether a typical "structural property" has its own proper contraries—whether there is a plurality of other properties, with which it contrasts to greater and lesser (but commensurable) extents. The answer pretty clearly seems to be Yes, at least in the case of some structural properties. 
"The methane property", for example, might differ to one degree from a structural property that features a silicon-atom part at the first conjunct, and to a greater degree from a structural property that features a germanium-atom part at that conjunct. The methane property might well differ in different ways-on other axes-from yet other structural properties. It would differ somewhat from a structural property that featured a lithium atom at just the second conjunct, and moreso from a structural property that featured a lithium atom at the second and third conjuncts (Wells 1972). There would be a question whether differences along the various axes (or dimensions) of difference can be commensurated with each other, and of whether one can calculate, from differences along two or more such axes, a resultant overall difference between the two whole structural properties involved. But these questions might well be manageable. First, if all real properties are instantiated, or at least instantiable in accordance with physical law — and this certainly is an issue on which I must simply assume a position, not defend one!there may not be all that many other structural properties that are variants, on any dimensions of difference, on the methane property. Second, there is in principle no obstacle to calculating resultant overall difference (or contrast) between properties that contrast with one another on multiple dimensions. Suppose, for example, that the colors are real properties. (This too is a controversial issue on which, for the sake of discussion, I will simply assume an answer.) They contrast with one another on three different dimensions, namely hue, saturation, and brightness. Yet for all that there is a fairly clear measure of resultant, overall difference between colors as unitary wholes: the measure is distance within the Munsell color solid.

But now note that the structural properties that would essentially characterize typical UMC objects would not be like colors, and would not even be quite like the methane property. They would be like the methane property on the second formulation, but without the sixth conjunct-mere lists of parts, with no requirement on how the parts are related. What form would contrasts or differences between such structural properties assume? We can certainly envision cases in which one such property features an Alike part at its fifth conjunct, and another such property, just like the first one up through the first four conjuncts, features a B-like part at its fifth conjunct. But would the contrast here be just a contrast 
between the fifth conjuncts themselves, or would it amount to an overall contrast between the "host" structural properties as unitary wholes? One way to see the force of this question is to move just slightly in the direction of the "mere list" structural properties appropriate to UMC objects: consider an amplified version of the methane property, as it appears on the first formulation, to which we have added a sixth conjunct that reads, "and contains the Eiffel Tower". And now consider a number of variant structural properties that differ from "amplified methane" strictly in respect of this sixth conjunct. One reads “...and contains the Panthéon", another “...and contains the Hôtel Biron”, another "...and contains a worm in Danielson, Connecticut”, a fourth “...and contains a hamburger in Weehauken”. With respect to the sixth conjunct, we seem to have greater contrasts as we get to the end of this list, than we had at the start of the list. But are these greater contrasts contrasts between whole unitary structural properties, or just between sixth conjuncts? Certainly no difference whatever in how something acts is entailed by whether the structural property with "...and contains the Panthéon" is instantiated, or whether the one with “...and contains a hamburger in Weehauken" is instantiated instead: in either case you have a methane molecule acting like a methane molecule, and both the Panthéon and the hamburger sitting there like themselves. Differences with respect to color are differences with respect to how some unitary thing looks. Differences with respect to these "mere list" structural properties are not differences in how any unitary thing acts, not even some unitary but very large and spatially discontinuous thing.

The problem with "amplified methane" is that the sixth conjunct has nothing to do with the first five. That is why divergence with respect to the sixth conjunct amounts to divergence only with respect to the sixth conjunct, and not divergence from the structural property as a whole. One could replicate the very same problem with colors, by constructing a suitable conjunctive-though non-structural—property. Thus one might start with Red 16, and specify it as a three-fold conjunctive property: being located at such-and-such a point on the hue axis of the Munsell color solid, at such-and-such a point on the brightness axis, and at such-and-such a point on the saturation axis. Then one would add an unrelated fourth conjunct, such as "is located at longitude $10^{\circ} 43^{\prime}$ 0" East". Divergences from an object bearing this conjunctive property, with respect to any of the first three conjuncts, would make for an overall difference 
in how the bearer of that divergent property looks. Divergences with respect to the fourth conjunct would not make for any difference in how anything looks or in how anything acts.

But in the "mere list" structural properties that essentially characterize typical UMC objects, none of the conjuncts has anything to do with any of the others. Consequently there is little prospect of making out the claim that "mere list" structural properties can, as unitary wholes, differ to greater and lesser degrees from other structural properties. And if they cannot, it at least appears to follow that such properties do not, in their own right, have contraries of their own. It would follow that they are not really properties at all: that they are, precisely, mere lists of separate objects.

IV

But someone could charge that the above discussion "stacks the deck" against the structural properties that would characterize typical UMC objects, and that in two ways. For one thing, we have so far considered only the structural properties that would essentially characterize UMC objects, and these do indeed incorporate no requirements on relations among the parts of the UMC object. But even typical UMC objects—ones different from a synchronic fusion of atoms which just happens to have the color and shape of an orange ball, or from a synchronic fusion of atoms which just happens to be found exactly where common sense discerns a dog—will, at any given time, accidentally be such that their parts stand in some spatio-temporal relations to each other. Typical UMC objects will be characterized, albeit accidentally, by structural properties that are not "mere lists". Second, there may be something biased in the suggestion that if the structural properties that characterize UMC objects (whether essentially or accidentally) are to contrast with their own proper contraries, they must so contrast as unitary wholes. Perhaps it is just in the nature of these properties that they are sums of disjointed ways that disjointed things independently are. If so, contrasts obtaining between such properties are bound to be contrasts that obtain only between isolated conjuncts. 
In this section, then, we will consider properties that characterize UMC objects both essentially and merely accidentally. We will focus on the properties of typical UMC objects-objects that incorporate a vast number of widely scattered parts, in some cases parts that intuitively seem to belong to a diverse array of different ontological categories. But we will allow that one such a property can contrast with another such property just by virtue of containing a conjunct that differs from a conjunct in that other property. Since the structural properties that characterize typical UMC objects incorporate many, many conjuncts-thousands, let us say-it will follow that one such structural property can contrast with other structural properties on thousands of different dimensions.

What I will argue, however, is that this still will not be enough to show that there is contrariety among the structural properties that characterize typical UMC objects. Contrariety obtains only where a property differs from other properties to greater and lesser, but commensurable, degrees: there must be a well-defined phenomenon of "more and less different from". But the diversity of dimensions on which these structural properties diverge from one another keeps this phenomenon from obtaining, I shall argue. The key idea is that these structural properties are, formally, unlike colors. Colors diverge from one another on the three dimensions of hue, saturation, and brightness. But if, on the dimension of hue, color A diverges more from color $\mathrm{C}$ than from color $\mathrm{B}$, those differences in the degree to which $\mathrm{A}$ contrasts with $\mathrm{C}$ and $\mathrm{B}$ remain in place no matter how $\mathrm{A}$ compares with $\mathrm{C}$ and $\mathrm{B}$ on the other two dimensions. In this sense, the dimensions on which colors diverge from one another are additive. In contrast, the dimensions on which the structural properties we now are considering diverge from one another are mutually interfering. Structural property $S_{1}$ may diverge more from $S_{3}$ than from $S_{2}$, on some dimension of difference, but this very difference in divergences may amount to $S_{1}$ 's being more like $S_{3}$ than like $S_{2}$ more different from $S_{2}$ than from $S_{3}$-depending on how matters stand on other dimensions. I will illustrate this claim in a moment. The upshot is that while any one such structural property may lie at different distances from each of two others, on any dimension that appears to permit a comparison of degrees of difference from the first structural property, those different distances never in and of themselves amount to true cases of "more and less different" relating the structural properties in question. 
Indeed those different distances do not even make stable and fixed contributions to a phenomenon of greater and lesser difference. So while there are countless variants on $S_{1}$, which differ from $S_{1}$ itself in countless different ways, there is in general no phenomenon of "more and less" that orders those differences. Among such structural properties, there is no contrariety.

To illustrate, let $S_{1}$ be a structural property that characterizes a large and spatially discontinuous $\mathrm{UMC}$ object, all the parts of which are fundamental microparticles of physics. Each conjunct in $\mathrm{S}_{1}$ attributes, to some one microparticle, a particular charge or "color" or velocity or excitation state. Then compare $\mathrm{S}_{1}$ with two other structural properties.

$\mathrm{S}_{2}$. Each of its first 1000 conjuncts attributes to some one microparticle a feature that is slightly different, or in some cases moderately different, from the feature attributed by the corresponding conjunct in $S_{1}$.

$\mathrm{S}_{3}$. Each of its first 5000 conjuncts attributes to a microparticle a feature that is slightly different from the feature attributed by the corresponding conjunct in $S_{1}$.

At first blush, $S_{3}$ appears to be more different from $S_{1}$ than $S_{2}$ is. But what if $S_{2}$ further differs from $S_{1}$ in the way that $\mathrm{S}_{4}$ does?

$\mathrm{S}_{4}$. Each of its first 1000 conjuncts is exactly the same as the corresponding conjunct in $\mathrm{S}_{1}$, but $\mathrm{S}_{4}$ incorporates only 50 more conjuncts beyond these $-\mathrm{S}_{4}$ is a far less complex structural property than $S_{1}$.

In that case it seems that $S_{2}$ will be more different from $S_{1}$ than $S_{3}$ is. However, it all depends on whether $\mathrm{S}_{3}$ itself differs from $\mathrm{S}_{1}$ in the way that $\mathrm{S}_{5}$ does.

$S_{5}$. It is conjunct-for-conjunct the same as $S_{1}$ up through the first 3000 conjuncts, but it incorporates 18000 more conjuncts than $S_{1}$ does- $S_{5}$ is a vastly more complex structural property than $S_{1}$ is.

It seems plausible that if $S_{3}$ itself is similarly complex, it will after all be more different from $S_{1}$ than $S_{2}$ is, even if $S_{2}$ is as (relatively) simple as $S_{4}$ is. But what shall we say about $S_{5}$ itself? If $S_{3}$ is as complex as $S_{5}, S_{5}$ will be more like $S_{1}$ than $S_{3}$ is. But is $S_{5}$ more like $S_{1}$ than $S_{2}$ is, or less? The same sort of question is posed (but from the other direction) by $\mathrm{S}_{6}$.

$\mathrm{S}_{6}$. It is conjunct-for-conjunct the same as $S_{1}$ up through its first 50 conjuncts, and these are the only conjuncts that it has.

Is $\mathrm{S}_{6}$ more like $\mathrm{S}_{1}$ than $\mathrm{S}_{2}$ is, or less? 
I said that in this section we would consider also some structural properties that are accidental to UMC objects. Here is an example:

$S_{7}$. It is conjunct-for-conjunct the same as $S_{1}$ up through the first 4000 conjuncts, but further conjuncts specify that each of the first 4000 conjuncts is satisfied at a point 1000 miles removed from all points at which any other of the first 4000 is satisfied.

$\mathrm{S}_{7}$ is not a "mere list" structural property: it also specifies a relation that obtains between the objects described by many of its conjuncts. Does this peculiarity of $S_{7}$ make it more like $S_{1}$ than it would otherwise be, or less like $S_{1}$ than it would otherwise be?

$\mathrm{S}_{7}$ is a property that could accidentally characterize either a synchronic fusion of microparticles, or a diachronic fusion. $\mathrm{S}_{8}$, in contrast, can characterize only a diachronic fusion.

$S_{8}$. It is conjunct-for-conjunct the same as $S_{1}$ up through the first 4000 conjuncts, but further conjuncts specify that each of the first 4000 conjuncts is satisfied at a time 500 years removed from all times at which any other of the first 4000 is satisfied.

It would be wrong to say that $S_{8}$ is an accidental property of some diachronic fusion. Any diachronic fusion is constituted by its associated "assignment", and so it is not the case that the parts of any one diachronic fusion could have been located at times other than those at which they actually are located. But $S_{8}$, like $S_{7}$, does specify a relation between the objects described by many of its conjuncts. Is $S_{8}$ more like $S_{1}$ than $S_{7}$, or less? How does its divergence from $S_{1}$ compare with the divergences from $S_{1}$ of $S_{2}-S_{6}$ ?

We must also consider divergences from $S_{1}$ that rest on a structural property's incorporating objects that seem to belong to different ontological categories from microparticles.

$\mathrm{S}_{9}$. Each of its first 1025 conjuncts is exactly the same as the corresponding conjunct in $S_{1} . \quad S_{9}$ incorporates 25 more conjuncts besides, and these are representative examples of the remaining 25: "and contains a part that has a boiling point of $202^{\circ} \mathrm{F}$ "; "and contains a part that requires on average 8.4 manhours to produce"; "and contains a part that has a lifetime batting average of .284".

$S_{10}$. Its first 15 conjuncts match exactly the first 15 conjuncts in $S_{1}$. It contains 25 more conjuncts beyond these, and these are representative samples: "contains a part has a height of over 10' when mature", "contains a part that is carnivorous", "contains a part that is highly resistant to penicillin". 
Is $S_{10}$ more like $S_{1}$ than $S_{9}$, or less? Intuitively, it seems that $S_{10}$ features "the wrong sort of conjunct" at just 25 places - and precisely the same is true of $S_{9}$. Is it decisive that there are proportionately more "wrong conjuncts" in $S_{10}$ than in $S_{9}$ ? If so, what does that say about the relation of $S_{5}$ to $S_{1}$ ?

What this extended illustration shows is that there is systematic interference among the various dimensions along which variants on a structural property $S_{n}$, characteristic of a typical UMC object, can differ from $S_{n}$ itself. The dimensions do not relate additively to one another. The consequence is that relative distances from $S_{n}$, along any dimension that appears to afford an ordering of "more and less different" for structural properties that are variants on $S_{n}$, will not in general amount, in and of themselves, to degrees of difference for those variant structural properties from $S_{n}$ itself.

For structural properties of the sort that would characterize typical UMC objects, there is no welldefined general phenomenon of "more and less different from". But then such properties are not related to one another by contrariety. But then those "properties" are not really genuine properties at all. If UMC objects existed, they would be characterized by no properties-there would be nothing that such objects are like, no way that each is. Consequently, UMC objects do not exist.

\section{V}

This paper has considered the thesis that, in addition to however many familiar objects there may be in the world—dogs, noses, and desks, for example—-there also are UMC objects. It has construed UMC objects as objects such that necessarily, they exist exactly when and where their actual parts existas objects for which mereological essentialism holds true. It has taken the prime reason for believing in UMC objects to be an argument that Sider adapts from Lewis. But philosophers who take more leaves from Lewis' book than just this single argument will be inclined to say that this paper has given a confused account of UMC objects-an account that is in one way too weak, and in another too strong. This section is a postscript addressed to the alternative account that these philosophers would favor. 
Too weak: one might hold that the Sider/Lewis argument shows that the only composite objects are mereological fusions; in other words, that the only form of composition is mereological composition. Many philosophers may think that if many microparticles are in spatial proximity to one another, or are causally integrated with one another, or together form a separately moveable mass of matter, then these factors—individually or in combination—entail that the microparticles together compose something. But there can be borderline cases of spatial proximity, of causal integration, and of separate moveability. Hence if these factors did suffice for composition, there could be borderline cases of composition. P3, in the Sider/Lewis argument, would be violated. Perhaps then there is only one factor sufficient, and only one factor required, for a plurality of microparticles - or a plurality of anything else-to compose something. This factor is that the elements of that plurality exist. If many objects exist, then thereby, automatically, they jointly compose something — and the existence of these objects is all that can make for composition.

Too strong: this paper has held that mereological essentialism holds true for any UMC object. But philosophers who subscribe to Lewis' counterpart theory will contest this claim. Might the very dog that stands before us - this very composite object—have existed, even if some of the microparticles that actually compose the dog had not existed at all? Counterpart theory seems to say: in the right conversational setting, the answer might well be yes. We consider a close possible world in which a few of the microparticles that actually compose this dog do not exist at all—or to speak more precisely, in which for a few of these microparticles, there are no counterpart microparticles. Even so, it could well be that a great many of the microparticles that actually compose this dog do have counterparts in that world, and that the counterpart microparticles are in close spatial proximity, are causally integrated with one another, and collectively move as a cohesive whole. As we envision this plurality of microparticles, we seem to see a dog that runs around and behaves much as the actual dog behaves. Then depending on the conversational setting, we might well be inclined to say that these microparticles together compose something. Indeed the something that these microparticles compose is so similar to the actual dog that we are inclined to say that this composite object "stands in" for the actual dog, and is our dog's counterpart. 
Presto: our dog really exists in a possible world in which some of its counterpart microparticles do not exist at all. Mereological essentialism, in this conversational setting, fails.

A similar scenario shows, these philosophers might argue, that it is not a necessary truth that our dog exists exactly where his actual component microparticles are found. Suppose that all the microparticles that compose the actual dog have counterparts, in some other close world, but that some of them are located on the moon. The vast majority of the counterpart-microparticles are causally integrated with one another in just the way that the microparticles in the actual dog are causally integrated, and cohere as a separately moveable (tail-wagging, barking) mass, just as are the microparticles in the actual dog. Then we might say (depending on the conversational setting) that these connected microparticles compose a dog, and indeed compose the very counterpart to our actual dog. Presto: it is possible that even though the microparticles actually composing our dog were somewhat scattered, our dog himself would exist only on earth and not partly on the moon-would exist as spatio-temporally continuous object.

I concede to these philosophers that we might in fact make such judgements about counterparts to our actual dog. But would these be the right judgements? Suppose we were to consider these close possible worlds in the light of the lessons that these philosophers draw from the Sider/Lewis argument. This does seem appropriate: if those are true lessons, then it cannot hurt to bear them in mind, if we seek to make true judgements about this dog's counterparts. Then we will judge that even if, in each of the possible worlds, certain microparticles are causally integrated and cohesively stuck together, forming a moveable object that looks and sounds just like our actual dog, all that has nothing whatever to do with whether these microparticles between them compose anything. All that is relevant, to whether many microparticles between them compose something, is whether those many microparticles exist, we will remind ourselves. All the same, we will indeed judge that there is a composite object located just where we have imagined ourselves envisioning a dog. It will be no more genuine than countless other composite objects located in those worlds, most which are discontinuous, and many of which overlap the location of the envisioned dog. But it will really exist. 
Yet should we judge that this composite object is the same composite object as our actual dogmore cautiously, that it is the counterpart to that actual composite object that is our actual dog? If all that renders our actual dog a genuine composite object is that all of his component microparticles exist, then it is hard to see how, in a world in which not all these component microparticles exist (i.e., have counterparts), we could have the same composite object as in the actual world (i.e., a true counterpart to the actual composite object). And what of the world in which some of the microparticle-counterparts are located on the moon? If all that renders our actual dog a genuine composite object is that all of his component microparticles exist, then it seems that the composite object in that world, that is the counterpart to our actual dog, is located partly on the moon.

The point here goes back to the way the Lewis/Sider argument is set up. Its topic is: can composition be restricted? The question is not whether composition can be extended-from familiar things to UMC objects. The starting presumption is that composition is found everywhere, in every plurality of objects, and the question is whether that presumption can be defeated. Why does that seem a reasonable starting presumption? Because UMC objects appear to be "an ontological free lunch". The existence of any such object seems just to be the existence of its parts. But so long as we cling clearly to this starting idea, it will be very hard to argue that such an object can exist despite the non-existence of some of its parts—or that it can exist in locations other than those occupied by its parts. ${ }^{5}$ 


\section{Footnotes}

${ }^{1}$ Is numerical sameness in the parts not only necessary but also sufficient for numerical sameness in the mereological sum-that is, is it a necessary truth that so long as numerically the same objects compose some mereological sum, they compose numerically the same mereological sum? "Yes" is the answer that best harmonizes with the idea that any mereological sum is an "ontological free lunch", and that is the answer that van Inwagen gives in his 1990 (pp. 75-78). But Michael Rea gives the opposite answer, even while claiming to be discussing mereological sums: Rea 1998, pp. 349-51.

${ }^{2}$ One interesting exception is Laycock 2006, p. 95-96.

${ }^{3}$ See section V.

${ }^{4}$ One family of eliminativist views hold that there are no objects in the world (Hawthorne and Cortens 1995), and that the world is "thingless" (Sidelle 1998), though it does contain primordial "stuff" (Sidelle 1989; Jubien 1993). Another family comprises views to the effect that there are only mereological simples or physical simples, and that composition does not occur (Unger 1979, p. 234; Wheeler 1979, p. 166; cf. Rosen and Dorr 2003). Closely related is the view that composition does not occur because there is only one thing, "the Blobject" (Horgan and Potrč 2000). More distantly related are views to the effect that there are only simples together with animals (van Inwagen 1990), or only simples together with conscious agents (Merricks 2001).

${ }^{5}$ [Acknowledgements deleted to preserve Author's anonymity.] 


\section{References}

Armstrong, D. M. 1997: A World of States of Affairs. Cambridge: Cambridge Univ. Press.

Baker, Lynne Rudder 2000: Persons and Bodies. Cambridge: Cambridge Univ. Press.

Balashov, Yuri 2006: “On Vagueness, 4D and Diachronic Universalism”. Australasian Journal of Philosophy, 83, pp. 523-31.

Bigelow, John and Pargetter, Robert 1990: Science and Necessity. Cambridge: Cambridge Univ. Press. Elder, Crawford 2004: Real Natures and Familiar Objects. Cambridge, Mass.: M.I.T. Press.

2001: "Mental Causation versus Physical Causation: No Contest," Philosophy and

Phenomenological Research, 62 (2001), pp. 111-127.

2000: “Physicalism and the Fallacy of Composition," Philosophical Quarterly, 50 (2000), pp. $332-43$.

Hawthorne, John O’Leary, and Cortens, Andrew 1995: “Towards Ontological Nihilism”. Philosophical Studies, 79, pp. 143-165.

Horgan, Terry and Potrč, Matjaž 2000: "Blobjectivism and Indirect Correspondence". Facta Philosophica, 2, pp. 249-70.

Hegel, G.W.F. 1969 (1831): Hegel's Science of Logic, trans. A. V. Miller. London: George Allen \& Unwin. 1970 (1830): Philosophy of Nature, trans. A. V. Miller. Oxford: Oxford Univ. Press. 1873 (1816): The Logic of Hegel, translated from The Encyclopaedia of the Philosophical Sciences by William Wallace. Oxford: Oxford Univ. Press.

Jubien, Michael 1993: Ontology, Modality, and the Fallacy of Reference. Cambridge Univ. Press.

Koslicki, Kathrin 2003: “The Crooked Path from Vagueness to Four-Dimensionalism”. Philosophical Studies, 114, pp. 107-34.

Laycock, Henry 2006: Words without Objects. Oxford: Oxford Univ. Press. 
Lewis, David 1986: On the Plurality of Worlds. Oxford: Blackwell.

1991: Parts of Classes. Oxford: Blackwell.

Lowe, E.J. 1989: Kinds of Being: a Study of Individuation, Identity and the Logic of Sortal Terms. Oxford: Blackwell. 1998: The Possibility of Metaphysics. Oxford: Oxford Univ. Press.

2003: "In Defense of Moderate-Sized Specimens of Dry Goods". Philosophy and Phenomenological Research, 57, pp. 705-710.

Merricks, Trenton 2001: Objects and Persons. Oxford: Oxford Univ. Press.

Rea, Michael 1997: Material Constitution: a Reader. Lanham, Maryland: Rowman and Littlefield. 1998: "In Defense of Mereological Universalism". Philosophy and Phenomenological Research, 58, pp. 347-60.

2002: World Without Design. Oxford: Oxford Univ. Press.

Rosen, Gideon and Dorr, Cian 2003: “Composition as a Fiction”. In The Blackwell Guide to Metaphysics, ed. Richard M. Gale. Oxford: Blackwell.

Sanford, David 2003: "Fusion Confusion”. Analysis, 63, pp. 1-4.

Saucedo, Raul forthcoming: "Parthood and Location." In Dean Zimmerman, ed., Oxford Studies in Metaphysics.

Sidelle, Alan 1989: Necessity, Essence, and Individuation. Ithaca: Cornell Univ. Press.

1998: “A Sweater Unraveled: Following One Thread of Thought for Avoiding Coincident Entities". Nous, 32, pp. 423-48.

Sider, Theodore 2001: Four-Dimensionalism: an Ontology of Persistence and Time. Oxford: Oxford Univ. Press.

Thomson, Judith Jarvis 1983: “Parthood and Identity Across Time”. Journal of Philosophy, 80, pp. 20120. 
Unger, Peter 1979: “I Do Not Exist.” In G. P. Macdonald, ed., Perception and Identity. Ithaca: Cornell Univ. Press, pp. 235-51.

Wheeler, Samuel 1979: “On That Which Is Not.” Synthese, 41, pp. 155-73

Van Inwagen, Peter 1990: Material Beings. Cornell Univ. Press. , 2006: “Can Mereological Sums Change their Parts?”. Journal of Philosophy, 103, pp. 614-30.

Wells, Alexander Frank 1962: Structural Inorganic Chemistry. Oxford: Oxford Univ. Press.

Wiggins, David 1980: Sameness and Substance. Cambridge, Mass.: Harvard Univ. Press. 